\title{
A Comparative study of metal replacement on doped L-isoleucine crystals
}

\author{
C. Kayalvizhi ${ }^{1}$, V.S. Kumar ${ }^{2 *}$, B. Samuel Ebinezer ${ }^{3}$, R.S. Sundararajan ${ }^{3}$ \\ ${ }^{1}$ Department of Physics, Government Arts College for women(Autonomous), Kumbakonam, Tamilnadu, India \\ ${ }^{2}$ Department of Physics, Swami Dayananda College of Arts and Science, Manjakkudi, Tiruvarur Dt.,Tamilnadu, India \\ ${ }^{3}$ Department of Physics, Government Arts College(Autonomous), Kumbakonam, Tamilnadu, India \\ "Corresponding author e-mail: shanmugavsk.2010@gmail.com
}

Available online at: www.isroset.org

Received:15/Sept/2018, Accepted:06/Oct/2018, Online: 31/Oct/2018

\begin{abstract}
Single crystals of zinc acetate doped isoleucine and cadmium acetate doped iso leucine crystals have been grown by slow evaporation technique. Good quality crystals were grown in 20 days. The fluorescence of the crystals were analyzed by fluorescence studies. FTIR spectrum reveals the functional groups of the crystals. The crystals have good optical nature in the intact UV-Visible region. SEM analysis reveals the structural morphology of crystals.
\end{abstract}

Keywords- LISZA - isoleucine zinc acetate; LISCA - isoleucine cadmium acetate; FTIR - Fourier transform infrared spectrum; UV-VIS region - Ultra Violet-Visible region

\section{INTRODUCTION}

A material which satisfies optical transparency is suitable for the opto-electronics device fabrication normally. It is very difficult to identify such a material with all requirements. Amino acid having acentric crystallographic structure with the absence of strong conjugated bonds leads to wide transparency in the entire UV-Visible region[1].

In this paper, the growth and characterization of a new material, L-isoleucine with the replacement of zinc acetate by cadmium acetate(LISCA) is discussed. The grown crystal is effectual in giving good optical, structural and fluorescence behavior which can be utilized for optoelectronic device fabrications.

\section{EXPERIMENTAL PROCEDURE}

\section{A. Synthesis}

High purity salts(99.9\%) were used for the crystal growth. Single crystals of zinc acetate doped isoleucine and cadmium acetate doped isoleucine were grown at room temperature by solution growth using slow evaporation method, of an aqueous solution containing pure iso leucine and zinc acetate with isoleucine in equal stoichiometric ratio. The temperature of water in the bath was controlled digitally by using microprocessor. Variation in temperature of the bath can be tuned to an accuracy of $\pm 0.1{ }^{\circ} \mathrm{C}$. Transparent good quality crystals of the title compound were harvested in the span of 20 days. The photograph of the LISZA and LISCA crystals are shown in fig.1.

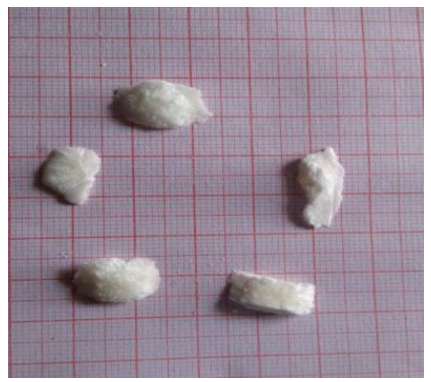

Fig.1(a) Photograph of LISCA

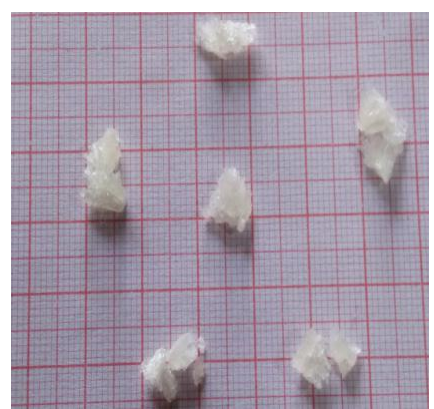

Fig.1(b) Photograph of LISZA 


\section{CHARACTERIZATION}

The fluorescence studies of the grown LISZA and LISCA crystals were carried out using LS45 spectrofluorometer.. FTIR spectrum analysis was recorded in the range of 4000$400 \mathrm{~cm}^{-1}$ using Perkin Elmer spectrum RX I. The UVVisible spectrum was recorded in the range $200 \mathrm{~nm}-1100 \mathrm{~nm}$ using Perkin Elmer lambda 35 model. The surface morphology of the crystals were compared using Scanning Electron Microscope.

\section{RESULTS AND DISCUSSION}

\section{A. Fluorescence studies}

Property of fluorescence is used to determine the crystalline quality as well as its exciton and thereby fine structure. The fluorescence spectra of both crystals are observed and given in figure. The fluorescence emission spectra for LISZA and LISCA crystal samples were recorded in the range from 240 $-700 \mathrm{~nm}$. The broadband is centered at $454.35 \mathrm{~nm}$ with 808.89 for LISZA and $453.52 \mathrm{~nm}$ with 878.11 for LISCA.

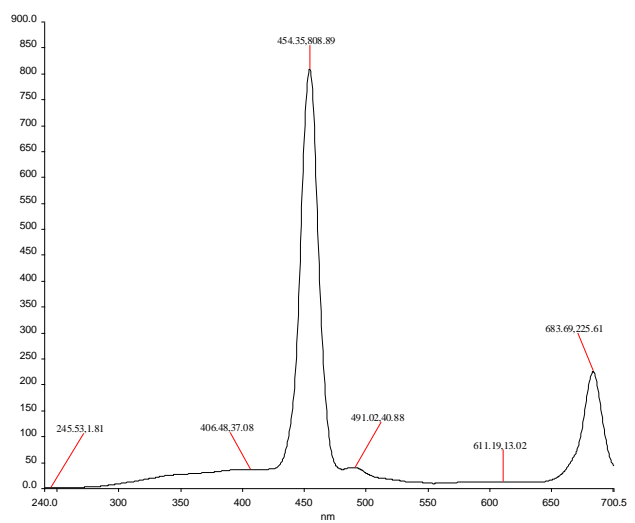

Fig.2(a) Fluorescence peak of zinc acetate with isoleucine

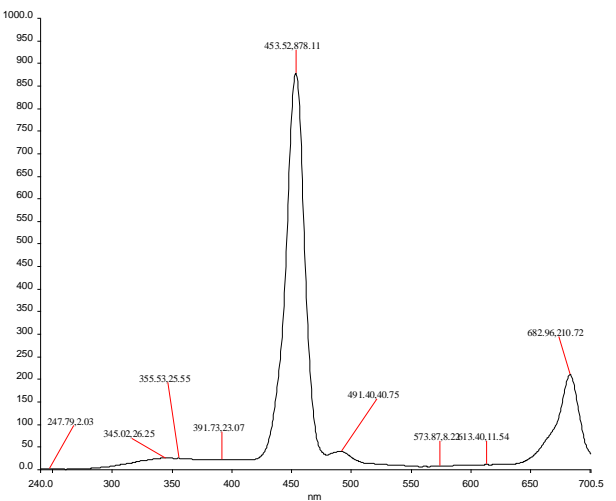

Fig.2(b) Fluorescence peak of cadmium acetate with isoleucine
An intensity peak at 808.89 was observed in the emission spectrum for LISZA and 878.11 for LISCA.

B. Fourier Transform Infrared spectrum studies The FTIR spectrum was recorded for the sample of the crystals using the $\mathrm{KBr}$ pellet technique in the region 4000$400 \mathrm{~cm}^{-1}$. The various functional groups present in the material are identified in this study[2-5]. The FTIR spectrum is shown in fig. 3 .

Table: Assignment modes from FTIR spectrum

\begin{tabular}{|c|c|c|c|}
\hline LISZA & LISCA & $\begin{array}{c}\text { L- } \\
\text { Isoleucine }\end{array}$ & Assignment mode \\
\hline 3258 & - & - & $\begin{array}{ll}\mathrm{N}-\mathrm{H} & \text { aminoacid } \\
\text { stretching } & \end{array}$ \\
\hline 3153 & 3154 & - & $\begin{array}{l}\mathrm{NH}_{3+} \quad \text { Asymmetric } \\
\text { stretching }\end{array}$ \\
\hline 2966 & 2967 & 2967 & $\begin{array}{l}\text { C-H stretching } \\
\text { vibration }\end{array}$ \\
\hline 2937 & 2937 & - & $\begin{array}{ll}\mathrm{C}-\mathrm{H} & \text { stretching } \\
\text { vibration } & \\
\end{array}$ \\
\hline 2879 & 2880 & 2880 & $\begin{array}{l}\text { Presence of free } \\
\text { amino acid with C-H } \\
\text { stretching }\end{array}$ \\
\hline 2621 & 2620 & 2618 & $\begin{array}{l}\text { Presence of } \\
\text { aminoacid(weak) } \\
\text { but not always }\end{array}$ \\
\hline- & 2347 & - & N-H streching \\
\hline- & 2322 & - & N-H streching \\
\hline 2112 & 2114 & 2114 & $\begin{array}{l}\mathrm{C}-\mathrm{C} \text { (triple bond) } \\
\text { stretching }\end{array}$ \\
\hline- & 1580 & - & $\mathrm{NH}_{3}$ deformation \\
\hline - & 1400 & - & $\begin{array}{l}\text { OH carboxylic acid In } \\
\text { plane (bending }\end{array}$ \\
\hline 1419 & 1418 & 1417 & $\begin{array}{l}\mathrm{CH}_{3} \text { symmetric } \\
\text { bending }\end{array}$ \\
\hline 1153 & - & - & C-C Rocking \\
\hline - & 993 & - & $\begin{array}{l}\mathrm{C}-\mathrm{H} \text { out of plane } \\
\text { deformation }\end{array}$ \\
\hline 922 & 921 & 921 & $\begin{array}{l}-\mathrm{O} \mathrm{C}\left(\mathrm{CH}_{3}\right) \text { skeletal } \\
\text { vibration }\end{array}$ \\
\hline 538 & 537 & 537 & $\mathrm{NO}_{2}$ deformation \\
\hline 442 & 443 & - & C-N-C bending \\
\hline
\end{tabular}




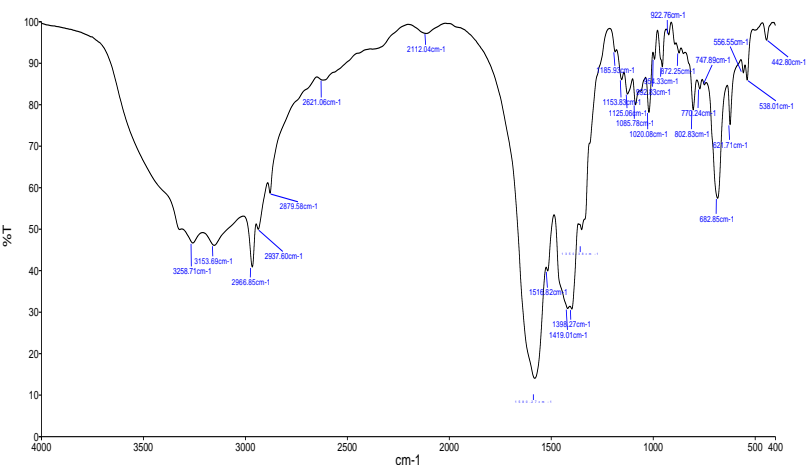

Fig.3(a) FTIR spectrum of LISZA

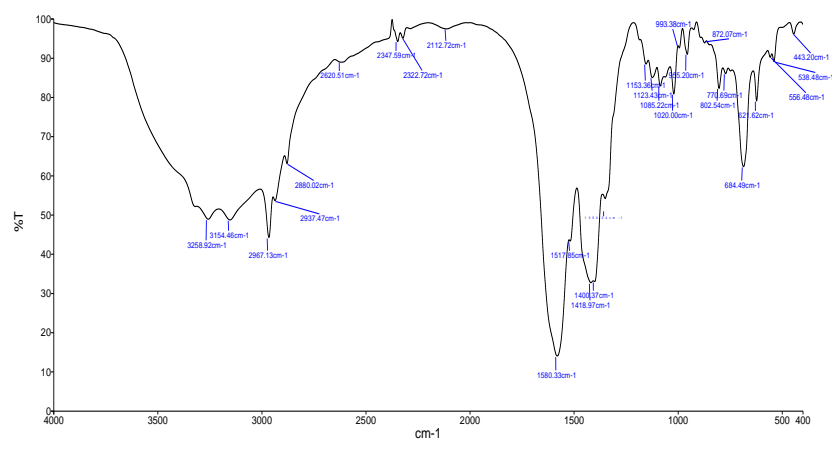

Fig.3(b) FTIR spectrum of LISCA

C. UV-Visible spectral studies

The optical absorption spectra of LISZA and LISCA crystals were recorded in the region 200-1100nm at a scanning speed of $480 \mathrm{~nm} / \mathrm{min}$. Fig. 4(a\&b) shows the absorbance spectra and transmission spectra which hold good in the entire visible region. The cutoff wavelength of LISCA was found to be $225 \mathrm{~nm}$ and $243 \mathrm{~nm}$ for LISZA. The optical behavior of this LISCA crystal was suitable for optoelectronic applications when compared to LISZA crystal.

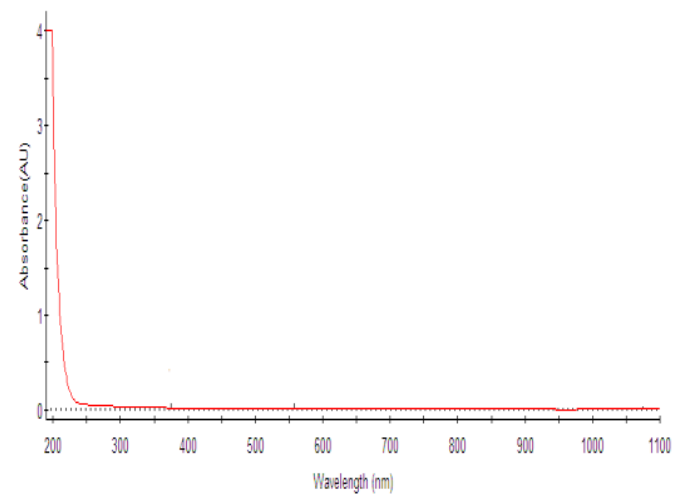

Fig.4(a) Absorption spectrum of LISZA

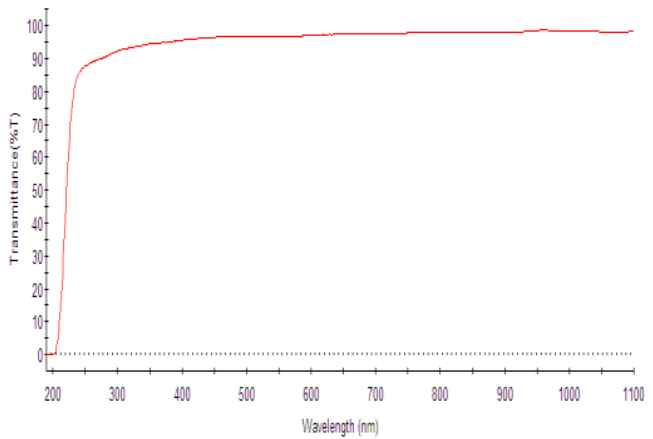

Fig.4(b) Transmission spectrum of LISZA

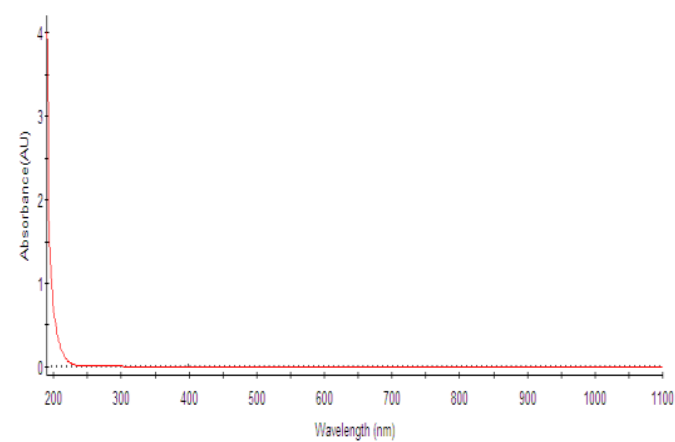

Fig.4(c) Absorption spectrum of LISCA

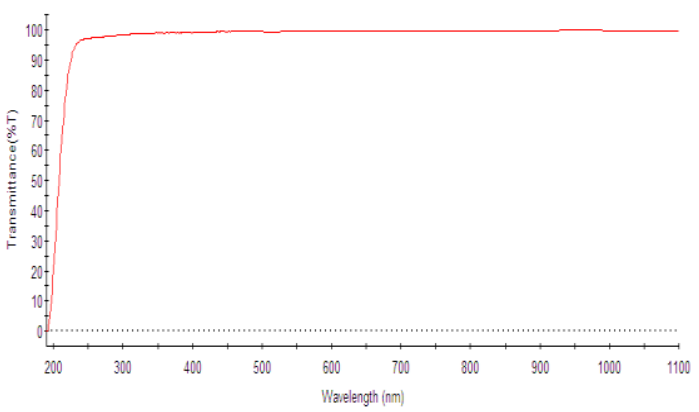

Fig.4(d) Transmission spectrum of LISCA

D. SEM analysis:

Fig.5(a) represents the zinc acetate mixed isoleucine crystal fabric. It has the intergranular fracture in its appearance, whereas fig.5(b) reveals the structural morphology of cadmium acetate mixed isoleucine crystal. This represents the capillary display thin filamentous diaphragmmed fenestral openings. 


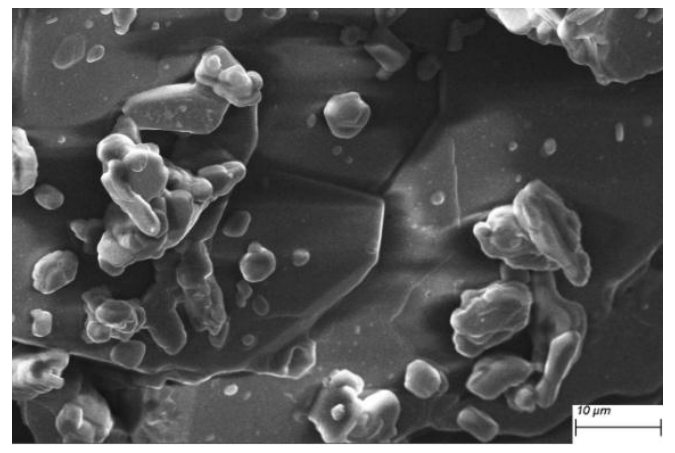

Fig.5(a) SEM image of LISZA

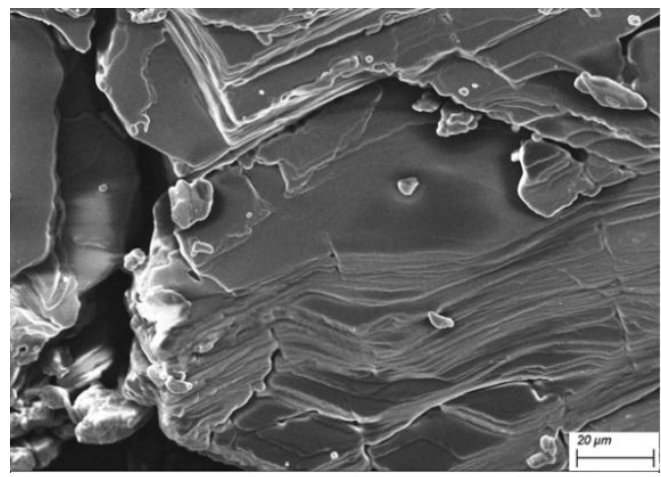

Fig.5(b) SEM image of LISCA

\section{CONCLUSION}

Single crystals of zinc acetate doped iso leucine and cadmium acetate doped iso leucine have been grown by slow evaporation technique. The fluorescence spectra of both crystals are observed. FTIR spectrum reveals the functional groups of the grown title compound material are upto hope. The crystal has good optical character in the entire UV-Visible region. SEM analysis discloses the structural morphology of LISZA and LISCA crystals. This new crystal material may be considered for opto electronic applications.

\section{ACKNOWLEDGEMENTS}

The authors are thankful to ACIC, St. Joseph's College for the spectral studies.

\section{REFERENCES}

[1] Tanusree K., Amino acids-precursors for synthesizing non linear optical.Mater.Prog.Cryst. Growth Ch.Mat., 2012, 58,74-83.

[2] George Socrates, Infrared and Raman Characteristics group frequencies Tables and Charts, $3^{\text {rd }}$ Edition.

[3] Foil A. Miller and Charles H. Wilkins, Infrared Spectra and characteristic frequencies of inorganics ions,vol.24.no.8Aug.1952[1253-1294].
[4] John Coates, Interpretation of Infrared spectra, A practical approach, Encyclopedia of analytical chemistry, John Wiley and son Ltd., Chichester(2000)[1-23].

[5] Jospeh B. Lambert,et.al, Introduction to organic spectroscopy, MacMillan Pub.NY(1987). 